\title{
DOES SURGEON SPECIALIZATION CHANGE THE PROXIMAL HUMERAL OSTEO-SYNTHESIS APPROACH?
}

\section{A ESPECIALIZAÇÃO MUDA A ESCOLHA DA VIA DE ACESSO PARA A OSTEOSSÍNTESE DE ÚMERO PROXIMAL?}

\author{
Guilherme Grisi Mouraria ${ }^{1}$, Plinio de Almeida Martins de Souza ${ }^{1}$, Ricardo lucca Cabarite Saheb ${ }^{1}$, Marcio Alves Cruz $^{1}$, \\ LuCAs Moratelli ${ }^{1}$, Mauricio ETCHebehere ${ }^{1}$
}

1. Universidade Estadual de Campinas (UNICAMP), Department of Orthopedics and Traumatology, Shoulder and Elbow Group, Campinas, São Paulo, Brazil.

\begin{abstract}
Objective: To evaluate the choice of surgical approach among Brazilian orthopedists and whether shoulder surgery specialty training or duration of experience influences the decision-making. Methods: A questionnaire on the preferred approach and complications was administered to orthopedic surgeons with and without shoulder specialization training. The chi-square test or Fisher's exact test was applied. Results: We interviewed 114 orthopedists, 49 (43.0\%) traumatologists, 36 (31.5\%) specialist surgeons, and 29 (25\%) shoulder surgery specialist residents. In cases of fracture without dislocation, specialized training and duration of experience did not influence the approach used (primarily deltopectoral). In cases of fracture/dislocation, $97.2 \%$ of the specialists versus $82.1 \%$ of the traumatologists opted for the deltopectoral approach $(p=0.034)$. In cases of fractures/dislocation, $92.5 \%$ of surgeons with more than 5 years of experience and $78.7 \%$ with less than 5 years of experience opted for the deltopectoral approach $(p=0.032)$. Conclusion: Specialization in shoulder surgery did not influence surgeons' approaches to manage fractures without dislocation. In cases of fracture/dislocation, shoulder surgery specialization training and duration of experience were associated with selection of the deltopectoral approach. Level of Evidence V, Expert opinion.
\end{abstract}

Keywords: Shoulder Fractures. Humeral head. Shoulder joint. Osteosynthesis.

\section{RESUMO}

Objetivo: Avaliar a via de acesso de escolha entre os ortopedistas brasileiros e se a formação de especialista em cirurgia do ombro e/ ou tempo de experiência influenciam nessa decisão. Métodos: Realizou-se questionário entre ortopedistas, com e sem especialização em ombro, sobre qual a via de acesso preferida e as complicações observadas. Aplicou-se o teste do qui-quadrado ou o teste exato de Fisher. Resultados: Foram entrevistados 114 ortopedistas, 49 (43,0 \%) traumatologistas, 36 (31,5\%) cirurgiões especialistas e 29 (25 \%) residentes de especialização em cirurgia do ombro. Nas fraturas sem luxação a formação especializada e o tempo de experiência não influenciaram na escolha (maioria deltopeitoral). Na fratura/luxação, $97,2 \%$ dos especialistas optaram pela deltopeitoral, comparado com $82,1 \%$ dos traumatologistas $(p=0,034)$. Nas fraturas/luxação, cirurgiões com experiência superior a 5 anos optaram pela deltopeitoral (92,5\%) e aqueles com menos de 5 anos optaram pela via deltopeitoral $(78,7 \%)(p=0,032)$. A diminuição do arco de movimento (ADM) foi a complicação mais relatada. Conclusão: A especialização em cirurgia do ombro não influenciou na escolha nas fraturas sem luxação. Na fratura/luxação, a especialização e o tempo de experiência associaram-se à escolha da via deltopeitoral. A complicação mais frequente foi a diminuição do ADM, principalmente entre os cirurgiões do Ombro. Nível de Evidência V, Opinião de especialistas.

Descritores: Fraturas do úmero proximal. Fraturas do ombro. Cabeça do úmero. Osteossíntese.

Citation: Mouraria GG, Souza PAM, Saheb RLC, Cruz MA, Moratelli L, Etchebehere M. Does surgeon specialization change the proximal humeral osteo-synthesis approach? Acta Ortop Bras. [online]. 2019;27(2):113-5. Available from URL: http://www.scielo.br/aob.

\section{INTRODUCTION}

Increased life expectancy and high-energy trauma increase the incidence of proximal humeral fractures. Most of these fractures are treated conservatively. However, fractures with dislocation may require surgical treatment. ${ }^{1,2}$

When possible, osteosynthesis is the option of choice in fractures with surgical indications in young and elderly patients. ${ }^{1}$
Two approaches are used in the osteosynthesis of proximal humeral fractures. The deltopectoral approach is easier to perform and less close to the axillary nerve. ${ }^{3}$ The anterolateral approach is performed between the anterior and middle deltoid portions and features better exposure of the lateral region of the humerus. It can be performed in an extended manner by isolating and directly observing the axillary nerve or using the minimally invasive plate osteosynthesis (MIPO)

All authors declare no potential conflict of interest related to this article.

The study was conducted at the Universidade Estadual de Campinas (UNICAMP), Department of Orthopedics and Traumatology, Shoulder and Elbow Group, Campinas, São Paulo, Brazil. Correspondence: Plínio de Almeida Martins de Souza, HC-UNICAMP, Department of Orthopedics and Traumatology, Rua Tessalia Vieira de Camargo, 126, Barão Geraldo, Campinas 13083-970, SP, Brazil. plinio.ams@gmail.com 
technique, in which the axillary nerve is indirectly protected. Thus, although the anterolateral approach provides better access to the greater tuberosity and the lateral face of the humerus, the axillary nerve must be directly or indirectly protected. ${ }^{4,5}$

There are several international studies on osteosynthesis of proximal humeral fractures with blocked plates. The main studies included patients treated using the deltopectoral and lateral anteroposterior approaches and the MIPO technique. The extended anterolateral approach was used in few studies because surgeons tend to avoid manipulating the axillary nerve. ${ }^{6,7}$ However, no study in the Brazilian literature to date has investigated whether experience (training time) or shoulder surgery specialization can influence the choice of approach to treat osteosynthesis of proximal humeral fractures. Thus, this study aimed to investigate Brazilian orthopedic surgeons' choice of approach for osteosynthesis of proximal humeral fractures and to evaluate whether shoulder surgery specialist training influences this decision.

\section{MATERIALS AND METHODS}

A questionnaire was administered to orthopedists at two instances: in the Brazilian Congress of Orthopedic Trauma - Brasília/DF in 2017 to orthopedists without shoulder surgery specialization training (identified as traumatologists) but with the title of specialist by the Brazilian Society of Orthopedics and Traumatology in the closed meeting in 2017 - Trancoso/Bahia (meeting only among specialists with a title recognized by the Brazilian Society of Shoulder and Elbow Surgery); and among orthopedists who completed the shoulder surgery specialization in 2016 (shoulder residents). The project received approval from the local research ethics committee (number 90910818.7.0000.5404).

The questions were: How long has the surgeon been performing osteosynthesis of proximal humeral fractures (less than 5 years, between 5 and 10 years, and more than 10 years)? In fractures of the proximal humerus (without dislocation), what would be the preferred approach. In fractures associated with dislocation of the proximal humerus, what would be the preferred approach? Which implant is used in osteosynthesis of proximal humeral fractures? Which are the main complications observed in the postoperative of proximal humeral fractures? Questionnaires that were not fully answered were excluded. The chi-square test or Fisher's exact test was used to compare the answers among the different professionals. All analyses were performed using PASW Statistics 18.0 (SPSS Inc., Chicago, IL, USA), using a significance level of $5 \%(P<0.05)$. All participants signed an informed consent form before completing the questionnaire.

\section{RESULTS}

Among the 114 interviewed orthopedists, 49 (43.0\%) were traumatologists, 36 (31.5\%) were shoulder surgery specialists, and 29 (25\%) were shoulder surgery specialist residents.

For fractures without dislocation of the humeral head, $81.6 \%$ of the respondents preferred the deltopectoral approach. Shoulder surgery training did not influence the choice of approach, which was mostly deltopectoral (Table 1). Duration of professional experience also did not interfere with the choice of approach (Table 2).

In cases of fractures associated with humeral head dislocation, most shoulder specialists opted for the deltopectoral approach. Considering the resident shoulder specialists and the shoulder surgery specialists (97.2\%), more professionals chose the deltopectoral approach compared to traumatologists (82.1\%) $(p=0.034)$ (Table 3). There was an association between the chosen approach and the surgical experience in the treatment of proximal humeral fractures. A total of $92.5 \%$ of the surgeons with more than 5 years of experience opted for the deltopectoral approach, while $78.7 \%$ of the surgeons with less than 5 years of experience opted for the deltopectoral approach ( $p=0.032)$ (Table 4).

Residents who recently specialized in shoulder surgery primarily chose the deltopectoral approach, especially when the fracture was associated with dislocation (86.2\%). In the absence of dislocation, $79.3 \%$ of them chose the deltopectoral approach.

The locked plate was the implant of choice among professionals regardless of the surgeon's training and experience duration (Table 5). The decrease in shoulder range of motion was the most commonly reported complication, especially by shoulder specialists (Table 6).

\begin{tabular}{|c|c|c|c|c|}
\hline & \multirow{2}{*}{$\mathbf{n}$} & \multicolumn{2}{|c|}{ Preferred approach } & \multirow{2}{*}{$p$} \\
\hline & & Anterolateral & Deltopectoral & \\
\hline Traumatologist & 49 & $10(20.4 \%)$ & $39(79.6 \%)$ & 0.698 \\
\hline Shoulder surgeon & 36 & $5(13.9 \%)$ & $31(86.1 \%)$ & \\
\hline Shoulder resident & 29 & $6(20.7 \%)$ & $23(79.3 \%)$ & \\
\hline Traumatologist & 49 & $10(20.4 \%)$ & $39(79.6 \%)$ & 0.635 \\
\hline \multirow[t]{2}{*}{ Shoulder surgeon or resident } & 65 & $11(16.9 \%)$ & $54(83.1 \%)$ & \\
\hline & 114 & $21(18.4 \%)$ & $93(81.6 \%)$ & \\
\hline
\end{tabular}

Table 2. Approach used according to duration of surgical experience for fractures without dislocation.

\begin{tabular}{c|c|c|c|c}
\hline & \multirow{2}{*}{$\mathbf{n}$} & \multicolumn{2}{|c|}{ Preferred approach } & \multirow{2}{*}{$\mathbf{p}$} \\
\cline { 3 - 4 } & & Anterolateral & Deltopectoral & \\
\hline Up to 5 years & 47 & $9(19.1 \%)$ & $38(80.9 \%)$ & 0.170 \\
\hline Between 5 and 10 years & 21 & $1(4.8 \%)$ & $20(95.2 \%)$ & \\
\hline More than 10 years & 46 & $11(23.9 \%)$ & $35(76.1 \%)$ & \\
\hline Up to 5 years & 47 & $9(19.1 \%)$ & $38(80.9 \%)$ & 0.867 \\
\hline More than 5 years & 67 & $12(17.9 \%)$ & $55(82.1 \%)$ & \\
\hline Up to 10 years & 68 & $10(14.7 \%)$ & $58(85.3 \%)$ & 0.213 \\
\hline More than 10 years & 46 & $11(23.9 \%)$ & $35(76.1 \%)$ & \\
\hline & 114 & $21(18.4 \%)$ & $93(81.6 \%)$ & \\
\hline
\end{tabular}

Table 3. Approach used according to training time for fractures associated with dislocation.

\begin{tabular}{c|c|c|c|c}
\hline & \multirow{2}{*}{$\mathbf{n}$} & \multicolumn{2}{|c|}{ Preferred approach } & \multirow{2}{*}{$\mathbf{p}$} \\
\cline { 3 - 4 } & & Anterolateral & Deltopectoral & \\
\hline Traumatologist & 49 & $10(20.4 \%)$ & $39(79.6 \%)$ & 0.059 \\
\hline Shoulder surgeon & 36 & $1(2.8 \%)$ & $35(97.2 \%)$ & \\
\hline Resident & 29 & $4(13.8 \%)$ & $25(86.2 \%)$ & \\
\hline Traumatologist & 49 & $10(20.4 \%)$ & $39(79.6 \%)$ & 0.047 \\
\hline Shoulder surgeon or resident & 65 & $5(7.7 \%)$ & $60(92.3 \%)$ & \\
\hline & 114 & $14(12.3 \%)$ & $100(87.7 \%)$ & \\
\hline
\end{tabular}

Table 4. Approach used according to duration of surgical experience for fractures associated with dislocation.

\begin{tabular}{c|c|c|c|c}
\hline & \multirow{2}{*}{$\mathbf{n}$} & \multicolumn{2}{|c|}{ Preferred approach } & \multirow{2}{*}{$\mathbf{p}$} \\
\cline { 3 - 4 } & & Anterolateral & Deltopectoral & \\
\hline Up to 5 years & 47 & $10(21.3 \%)$ & $37(78.7 \%)$ & $0.090^{*}$ \\
\hline Between 5 and 10 years & 21 & $1(4.8 \%)$ & $20(95.2 \%)$ & \\
\hline More than 10 years & 46 & $4(8.7 \%)$ & $42(91.3 \%)$ & \\
\hline Up to 5 years & 47 & $10(21.3 \%)$ & $37(78.7 \%)$ & $0.032^{*}$ \\
\hline More than 5 years & 67 & $5(7.5 \%)$ & $62(92.5 \%)$ & \\
\hline Up to 10 years & 68 & $11(16.2 \%)$ & $57(83.8 \%)$ & $0.276^{\star *}$ \\
\hline More than 10 years & 46 & $4(8.7 \%)$ & $42(91.3 \%)$ & \\
\hline & 114 & $15(13.2 \%)$ & $99(86.8 \%)$ & \\
\hline
\end{tabular}

${ }^{\star}$ Chi-square text, Fisher's exact test. ${ }^{\dagger} \mathrm{A}$ case with two approaches was included. 
Table 5. Most commonly used implants according to preference or availability.

\begin{tabular}{c|c|c|c|c}
\hline & \multirow{2}{*}{$\mathbf{n}$} & \multicolumn{2}{|c|}{ Implants for normal use } & \multirow{2}{*}{$\mathbf{p}$} \\
\cline { 3 - 5 } & & $\begin{array}{c}\text { Used locked plates } \\
\text { ( other implants) }\end{array}$ & $\begin{array}{c}\text { Did not use } \\
\text { locked plates }\end{array}$ & \\
\hline Traumatologist & 49 & $43(87.8 \%)$ & $6(12.2 \%)$ & $0.844^{*}$ \\
\hline Shoulder surgeon & 36 & $33(91.7 \%)$ & $3(8.3 \%)$ & \\
\hline Resident & 29 & $26(89.7 \%)$ & $3(10.3 \%)$ & \\
\hline & 114 & $102(89.5 \%)$ & $12(10.5 \%)$ & \\
\hline
\end{tabular}

Table 6. Most frequently reported complications.

\begin{tabular}{c|c|c|c|c}
\hline & \multirow{n}{*}{} & \multicolumn{2}{|c|}{ Most observed complications } & \multirow{2}{*}{ p } \\
\cline { 3 - 4 } & & $\begin{array}{c}\text { Decreased range } \\
\text { of motion }\end{array}$ & $\begin{array}{c}\text { Another } \\
\text { complication }\end{array}$ & \\
\hline Traumatologist & 49 & $42(85.7 \%)$ & $7(14.3 \%)$ & $0.064^{*}$ \\
\hline Shoulder surgeon & 36 & $34(94.4 \%)$ & $2(5.6 \%)$ & \\
\hline Shoulder resident & 29 & $29(100 \%)$ & $0(0.0 \%)$ & \\
\hline & 114 & $105(92.1 \%)$ & $9(7.9 \%)$ & \\
\hline
\end{tabular}

Other complications frequently observed: osteonecrosis of the humeral head $(n=5)$, europraxia $(n=2)$, others unspecified $(n=1)$, does not follow the postoperative period $(n=1)$.

Axillary nerve neuropraxia was the most frequently reported complication $(n=3)$, all of whom performed the deltopectoral approach. No surgeon who performed the anterolateral approach, regardless of specialization, mentioned axillary nerve neuropraxia as a frequent complication.

\section{DISCUSSION}

Osteosynthesis of proximal humeral fractures is the option of choice for elderly patients when adequate fracture stabilization is possible and in cases of a low risk of avascular necrosis of the humeral head. ${ }^{1}$ It is also the option of choice in young patients. ${ }^{8}$

The surgeons preferred the deltopectoral approach, a result that corroborates with the literature., ${ }^{3,9}$ The preference for the deltopectoral approach among international surgeons is due to the exposure provided and the avoidance of dissection of the axillary nerve, which is necessary for the anterolateral approach. ${ }^{10}$ However, some authors have already demonstrated safety of the anterolateral approach as well as the low chance of axillary nerve injury. ${ }^{10-12}$ Moreover, this approach facilitates exposure of the lateral humeral surface and identification of major tuberosity fractures that are subsequently dislocated. ${ }^{10}$

The anterolateral approach makes medial exposure of the shoulder difficult and should be avoided in fractures with dislocations. ${ }^{10}$ Thus, this study showed that shoulder surgery specialization training time longer than 5 years led to the more frequent selection of the deltopectoral approach than the anterolateral approach. Thus, specialization and longer experience positively influenced the appropriate choice of approach.

Most residents who recently graduated from shoulder surgery specialized also opted for the deltopectoral approach, which shows a tendency of training centers to teach this approach to surgeons. Most surgeons chose to use a blocked plate. The blocked implant is the option of choice in the osteosynthesis of proximal humeral fractures since most cases are osteoporotic patients or those with comminuted fractures. Blocked implants provide greater biomechanical stability. ${ }^{1}$ Osteosynthesis also has a lower rate of complications than arthroplasty, especially reverse osteosynthesis. Moreover, in cases of failure after osteosynthesis, conventional or reverse arthroplasty is still possible with little functional difference and similar complication rates compared to those for primary reverse prosthesis in fracture treatment. ${ }^{13}$

The complication most commonly reported by the respondents was decreased range of motion, especially by shoulder surgery specialists, a finding that corroborates with the literature. Decreased range of motion, function, and shoulder strength are frequent complications after proximal humeral fractures, especially in cases of comminuted/Neer IV fractures and cases of osteonecrosis with joint penetration by screws. $3,14,15$

Axillary nerve neuropraxia was poorly reported by surgeons. Furthermore, despite being much feared in the anterolateral approach, no respondent who performed this approach reported that axillary nerve lesion was the more frequent complication. The literature also shows that regardless of the technique used (MIPO or direct exposure) performed with the anterolateral approach, there is little chance of nerve injury. ${ }^{16,17}$

AUTHORS' CONTRIBUTIONS: Each author contributed individually and significantly to the development of this article. GGM (0000-0002-8258-5350)* performed the surgeries and wrote and reviewed the article; PAMS (0000-0001-8832-4760)* performed the surgeries, analyzed the data, and wrote the article; RLCS (0000-0001-5914-5026** performed the surgeries and wrote and reviewed the article; LM (0000-0002-6584-5333)* performed the statistical analysis and reviewed the article; MAC (0000-0001-9074-9186)* performed the surgeries and reviewed the article; ME (0000-0002-5176-2369)* performed the surgeries, wrote the article, performed the statistical analysis, conceived the article, and prepared the entire research project. ${ }^{\star} \mathrm{ORCID}(\mathrm{Open}$ Researcher and Contributor ID).

\section{REFERENCES}

1. Thanasas C, Kontakis G, Angoules A, Limb D, Giannoudis P. Treatment of proximal humerus fractures with locking plates: A systematic review. J Shoulder Elb Surg. 2009;18(6):837-44.

2. Südkamp N, Bayer J, Hepp P, Voigt C, Oestern H, Kääb M, et al. Open Reduction and Internal Fixation of Proximal Humeral Fractures with Use of the Locking Proximal Humerus Plate. J Bone Jt Surg Am. 2009;9(16):1320-8.

3. Sohn H-S, Jeon YS, Lee J, Shin S-J. Clinical comparison between open plating and minimally invasive plate osteosynthesis for displaced proximal humeral fractures: A prospective randomized controlled trial. Injury. 2017;48(6):1175-82.

4. Brunner A, Thormann S, Babst R. Minimally invasive percutaneous plating of proximal humeral shaft fractures with the Proximal Humerus Internal Locking System (PHILOS). J Shoulder Elb Surg. 2012;21(8):1056-63.

5. Gardner MJ, Griffith MH, Dines JS, Lorich DG. A minimally invasive approach for plate fixation of the proximal humerus. Bull Hosp Jt Dis. 2004;62(1-2):18-23.

6. Laflamme GY, Rouleau DM, Berry GK, Beaumont PH, Reindl R, Harvey EJ. Percutaneous Humeral Plating of Fractures of the Proximal Humerus: Results of a Prospective Multicenter Clinical Trial. J Orthop Trauma. 2008;22(3):153-8.

7. Shin S-J, Kim JK, Koh YW. Minimally Invasive Plate Osteosynthesis for Proximal Humeral Fractures: A Prospective Study of Clinical and Radiological Outcomes According to Fracture Type. J Shoulder Elb Surg. 2015;24(8):e229.

8. Sproul RC, lyengar JJ, Devcic Z, Feeley BT. A systematic review of locking plate fixation of proximal humerus fractures. Injury. 2011;42(4):408-13.

9. Buecking B, Mohr J, Bockmann B, Zettl R, Ruchholtz S. Deltoid-split or deltopectoral approaches for the treatment of displaced proximal humeral fractures?
Clin Orthop Relat Res. 2014:472(5):1576-85.

10. Gardner MJ, Boraiah S, Helfet DL, Lorich DG. The anterolateral acromial approach for fractures of the proximal humerus. J Orthop Trauma. 2008;22(2):132-7.

11. Oh HK, Cho DY, Choo SK, Park JW, Park KC, Lee J. Lessons learned from treating patients with unstable multifragmentary fractures of the proximal humerus by minimal invasive plate osteosynthesis. Arch Orthop Trauma Surg. 2015;135(2):235-42.

12. Imarisio D, Trecci A, Sabatini L, Scagnelli R. Treatment for proximal humeral fractures with percutaneous plating: Our first results. Musculoskelet Surg. 2013;97(Suppl 1):85-91.

13. Shannon S, Wagner E, Houdek TM, Sotel JS. Reverse shoulder arthroplasty for proximal humeral fractures: outcomes comparing primary reverse arthroplasty for fracture versus reverse arthroplasty after failed osteosynthesis. J Shoulder Elbow Surg. 2016;25(10):1655-60.

14. Zirngibl B, Biber R, Bail HJ. Humeral head necrosis after proximal humeral nailing: what are the reasons for bad outcomes? Injury. 2016;47(Suppl 7):S10-3.

15. Schnetzke M, Bockmeyer J, Porschke F, Studier-Fischer S, Grützner PA, Guehring T. Quality of reduction influences outcome after locked-plate fixation of proximal humeral type-C fractures. J Bone Jt Surg Am. 2016:98(21):1777-85.

16. Buecking B, Mohr J, Bockmann B, Zettl R, Ruchholtz S. Deltoid-split or deltopectoral approaches for the treatment of displaced proximal humeral fractures? Clin Orthop Relat Res. 2014;472(5):1576-85.

17. Wu CH, Ma CH, Yeh JJH, Yen CY, Yu SW, Tu YK. Locked plating for proximal humeral fractures: Differences between the deltopectoral and deltoid-splitting approaches. J Trauma. 2011;71(5):1364-70. 